\title{
Thyroid Tuberculosis Mimicking an Anaplastic Carcinoma: A Rare Presentation
}

\author{
Said Anajar*, Mezzouki Boutaina, Reda Abada, Sami Rouadi, Mohammed Roubal and Mohammed Mahtar \\ Service ORL et chirurgie cervico-faciale, Hôspital 20 Août, Morocco
}

Submission: April 17, 2017; Published: April 28, 2017

*Corresponding author: Said Anajar, Service ORL et chirurgie cervico-faciale, Hôpital 20 Août, Casablanca Maroc, Bd Bordeaux Rue ait Baha N5, Maroc Morocco, Tel: 212660782808; Email: anajar.said.med@gmail.com

\begin{abstract}
Isolated tuberculosis of the thyroid gland is extremely rare with a few reported cases so far. When it does occur, it may seem difficult to diagnose due to non-specific and various clinical manifestations of tuberculous thyroiditis. Thyroid Tuberculosis simulating an anaplastic carcinoma appears to be the rarest and the most dangerous presentation. We report a case of a 70 year-old female who presented with a left lateral neck swelling for 4 months duration with no compression signs neither thyroid dysfunction nor other associated general signs. Cervical CT scan showed a left heterogeneous lateral neck mass invading the isthmus and the left thyroid lobe plunging into the sub clavicular region which was consistent with an anaplastic cancinoma. Histopathological examination was compatible with tuberculosis. The patient was then put under anti-tuberculous drug treatment for 6 months duration with a remarkable clinical improvement.
\end{abstract}

Keywords: Thyroid; Tuberculosis; Thyroiditis; Anaplastic carcinoma

\section{Introduction}

Tuberculosis is a chronic bacterial infection caused by Mycobacterium tuberculosis organisms. Thyroid Tuberculosis (TTB) is a rare extra pulmonary form of tuberculosis, initially described by Lebert in 1862 [1]. The incidence of TTB is estimated to be $0.1-1 \%$ in clinical series and between 2 and $7 \%$ on autopsy data [2-3]. The presence of Mycobacterium tuberculosis or the existence of specific histological lesions in the thyroid tissue defines the diagnosis of TTB [2]. This entity may have various clinical manifestations which makes the diagnosis difficult. Antituberculous drugs are the mainstay of treatment that often lead to a complete resolution of the infection and the prognosis depends on other associated sites. The aim of our work is to present a rare form of thyroid tuberculosis mimicking an anaplastic thyroid carcinoma and we discuss through a brief review of the literature the diagnosis and management modalities of the disease.

\section{A Case Presentation}

A 70 year-old female, with a medical history of high blood pressure and Diabetes Mellitus under treatment and no personal history of tuberculosis was referred to the otorhinolaryngology clinic with a complaint of a left lateral neck swelling evolving gradually for 2 months with no associated difficulty in swallowing or breathing. She also complained of a low-grade fever and weight loss during this period. On local examination, there was a solid to firm left mass measuring approximately
$4 \mathrm{~cm}$ of large diameter, fixed to both underlying structures and the overlying skin, with a slightly inflammatory appearance of this latter (Figure 1). Cervical CT scan showed a left lateral mass infiltrating the isthmus and the left thyroid lobe and plunging into the subclavicular region with a heterogeneous density appearance and irregular blurred contours. The process invaded also the subcutaneous tissues and deflected the trachea to the right side (Figure 2).

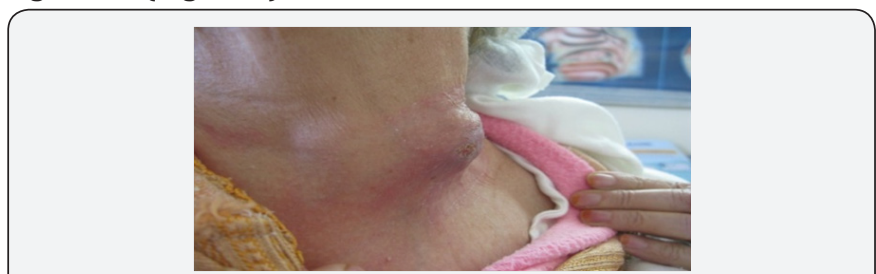

Figure 1: Left cervical mass with infiltrated and inflammatory skin.

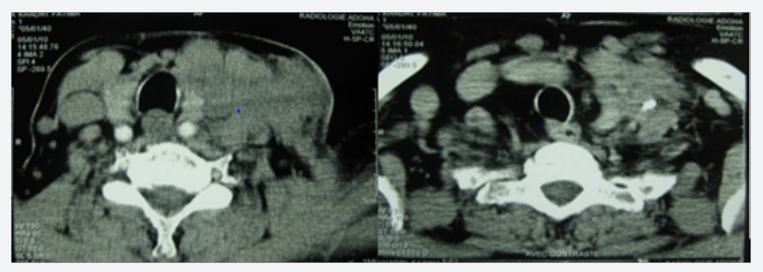

Figure 2: Neck CT scan- axial sections- Left cervical tissue mass invading the isthmus and the left lobe of the thyroid gland extending to the sub clavicular region. 
An incisional biopsy was performed. The histopathologic study revealed a very fibrous inflammatory tissue with a large areas of granulomatous inflammation with so many epithelioid and giant cells inside, and small foci of caseous necrosis which was compatible with Tuberculosis despite the absence of acid fast bacilli in the specimen. Chest radiography showed no abnormalities and Gram stains on expectorations were negative. 4 weeks later, bacteriological cultures of the specimen were positive for Mycobacterium tuberculosis. The patient was put under Antituberculous drugs before having the results of the culture: a combination of Rifampicin, Isoniazid and Pyrazinamide for 2 months followed by Rifampicin and Isoniazid for 4 months. The patient remained asymptomatic and euthyroid till the last follow-up/ 2 months after completion of the treatment. The mass decreased enormously in size at that time.

\section{Discussion}

Tuberculosis of the thyroid gland is a very rare entity even in endemic countries such as Morocco. Initially described by Lebert in 1862 [1]. The exact prevalence of TTB varies from 0.1 to $1 \%$ of all cases, and ranges from 0.6 to $1.15 \%$ of FNAC's results when performed for isolated thyroid nodule in endemic areas (India). Mean age of onset is around third to fourth decades with females being the most affected [4]. The scarcity of this entity may be explained by so many resistive mechanisms of the thyroid gland including bactericidal property of colloid material, increased vascularity, the presence of iodine in the thyroid gland and the anti-tuberculous activity of thyroid hormones [5-6]. Recently, the incidence of thyroid tuberculosis seems increasing due to the routine practice of fine-needle aspiration cytology (FNAC) which had an important impact on its diagnosis and management.

TTB may be primary when isolated or secondary when associated with a disseminated disease which spreads directly from adjacent organs or by hematogenous route [6-7]. In our case, we reported a case of isolated TTB without other clinically or radiologically demonstrated locations. The diagnosis of TTB remains difficult except when clinical or biological indications (Tuberculosis contagion, personal or family history of tuberculosis, cutaneous fistula on physical examination, long duration of fever, associated inflammatory syndrome or other tuberculous sites such as pulmonary or lymph node tuberculosis) are present. Moreover, TTB may take several clinical aspects of a thyroid involvement, the patient may present with subacute thyroiditis, thyroid abscess or fever of unknown origin, multi nodular goiter or only an isolated nodule. It can also mimic thyroid malignancy as patient may have dysphagia, dysphonia and laryngeal nerve palsy [8]. An anaplastic carcinoma's presentation is exceptional [9]. An interesting point to note is that general signs may be lacking during the course of the disease.

At the onset of the disease, hyperthyroidism may occur as a result of the destruction of the parenchyma and the massive release of thyroid hormones. Subsequently, hypothyroidism may appear by a total destruction of the gland. Dysfunction of the thyroid gland in TTB is rarely reported. In most cases, thyroid function is normal (10), only 3 cases of hypothyroidism have been described [6-11], and one patient presented transient thyrotoxicosis preceding hypothyroidism [11]. The imaging techniques (Ultrasonography, thyroid CT or MRI) are not very useful in diagnosis. USG may show a frank abscess with internal echoes or hypoechoic or heterogeneous lesion similar to neoplastic lesion [12]. Most often, Cervical CT findings show an isolated nodule or heterogeneous multifocal goiter or a hypodense lesion with peripheral enhanced contours after contrast material injection. The presence of cervical lymphadenopathy is possible [13]. Radiological imaging still indicate precisely the thyroid origin of the lesion, specify its solid or liquid nature and its extension to the adjacent structures.

The diagnosis is usually made by FNAC or after histopathological examination of the resected surgical specimen when FNAC is negative [10]. The characteristic finding of epithelioid cell granulomas with caseous necrosis and acidfast bacilli provides an accurate cytological and bacteriological diagnosis [14]. Demonstration of central caseous necrosis on a biopsy is also a definite diagnostic feature [10] with Acid fast bacilli, if demonstrated ascertain the diagnosis. However, these remain non demonstrable in most TTB specimens [15]. In the present case, caseous necrosis with granulomas revealed on a biopsy sample has made the diagnosis of TTB.

Thyroid tuberculosis should be considered as a differential diagnosis of all thyroid diseases including an infectious thyroiditis or a subacute granulomatous thyroiditis. Granulomatous inflammation of thyroid can occur in TB, sarcoidosis, granulomatous thyroiditis, fungal infections or foreign body reactions. TTB should also be differentiated from thyroid malignancy but these two conditions may coexist [7]. Classic treatment of TTB has been based on antituberculous drugs associated with surgical drainage or removal of affected parts of the thyroid gland. Presently, only an appropriate antituberculous treatment is recommended and is sufficient for complete resolution of the infection [16]. Drainage or a surgical resection is required in the case of TTB associated with a large abscess. The medical treatment is based on the combination of three powerful antituberculous drugs: rifampin (R), isoniazid $(\mathrm{H})$ and pyrazinamide $(\mathrm{Z})[17,18]$. In our case, we applied the protocol 2RHZ / 4 HR with a remarkable clinical improvement after 2 months of the start of treatment. Patients developing sequellae of hypothyroidism require hormone replacement therapy and it should be prescribed based on the rate of TSH [18].

\section{Conclusion}

Though a rare entity, tuberculosis of the thyroid gland should be kept in mind especially in endemic countries. The diagnosis 
of TTB must be considered while managing a patient with a thyroid mass. As anti-tuberculosis therapy is efficacious, proper diagnosis by FNAC and histopathological examination could avoid aberrant diagnosis and eventually unnecessary surgical interventions. Prognosis of TTB is usually favorable, depends mainly on the severity of other tuberculous locations.

\section{Author Contributions}

All the authors participated in the care of the patient, and in the realization of the article. All authors have read and approved the final version of the manuscript.

\section{Acknowledgment}

For the staff of the ENT CHU IBN ROCHD CASABLANCA MOROCCO.

\section{References}

1. Lebert (1862) Die krankheiten der schilddüse und ihre Behandlung. Breslau.

2. BC Kang, S Lee, S Shim, H Choi, S Baek, et al. (2000) US and CT findings of tuberculosis of the thyroid Three case reports. Journal of Clinical Imaging 24(5): 283- 286.

3. A Ghosh, S Saha, B Bhattacharya, S Chattopadhay (2007) Primary tuberculosis of thyroid gland: a rare case report. American Journal of Otolaryngology. Head and Neck Medicine and Surgery 28: 267- 270.

4. I Surer, H Ozturk, S Cetinkursun (2000) Unusual Presentation of Tuberculosis Reactivation in Childhood : An Anterior Neck Mass. J Pediatr Surg 35: 1263-1265.

5. Arjun Baidya, Arijit Singha, Rana Bhattacharjee, Bibhas Saha Dalalm (2015) Tuberculosis of the thyroid gland: two case reports. Oxford Medical Case Reports 262-264.

6. Bulbuloglu E, Ciralik H, Okur E, Ozdemir G, Ezberci F, et al. (2006) Tuberculosis of the thyroid gland: review of the literature. World J Surg 30: 149-155.
7. Lourtet-Hascoet J, Le Grusse J, Fontaine S, Caron P (2015) Thyroid tuberculosis: a new case and review of the literature. Ann Endocrinol (Paris) 76(5): 635-637.

8. Pandit AA, Joshi AS, Ogale SB, Sheode JH (1997) Tuberculosis of thyroid gland. Ind J Tub 44: 205-207.

9. HO El Malki, M El Absi, R Mohsine, K Aït Taleb, MC Chefchaouni, et al. (2002) La tuberculose de la thyroïde. Diagnostic et traitement. Ann Chir $127: 385-387$

10. Majid U, Islam N (2011) Thyroid tuberculosis: a case series and a review of the literature. J Thyroid Res 2011: 359-864.

11. Luiz HV, Pereira BD, Silva TN (2013) Thyroid tuberculosis with abnormal thyroid function - case report and review of the literature. Endocr Pract 19(2): 44-49.

12. Rajesh Kumar Soni, Ajit Sinha (2015) Tuberculosis of the Thyroid-a Diagnostic Enigma. Indian J Surg 77(1): 179-181.

13. S Vaid, YYP Lee, S Rawat, A Luthra, D Shah, et al. (2010) Tuberculosis in the head and neck : a forgotten differential diagnosis. Clinical Radiology 65(1): 73-81.

14. Das DK, Pant CS, Chachra KL, Gupta AK (1992) Fine needle aspiration cytology diagnosis of tuberculous thyroiditis: a report of eight cases. Acta Cytol 36: 517-522.

15. Khan EM, Haque I, Pandey R (1993) Tuberculosis of the thyroid gland: a clinicopathological profile of four cases and review of the literature. Aust NZ J Surg 63(10): 807-810.

16. Uz-Zaman M, Hussain R, Mirza MK, Khan KA, Khan GM, et al. (2008) Isolated tuberculousthyroiditis assolitary thyroid nodule. J Coll Phys Surg Pak 18(2): 121-122.

17. A Oudidi, A Cherkaoui, Z. Zaki, H Hachimi, MN El Alami (2005) Tuberculose thyroïdienne. Ann Otolaryngol Chir Cervicofac 122(3): 150-153.

18. R Mssrouri, A Bouzerouata, MK Lahlou, S Benamr, B Chad (2007) Goître multinodulaire : une forme de tuberculose thyroïdienne dont le traitement est médical. J Chir 144.

\section{Your next submission with Juniper Publishers will reach you the below assets}

- Quality Editorial service

- Swift Peer Review

- Reprints availability

- E-prints Service

- Manuscript Podcast for convenient understanding

- Global attainment for your research

- Manuscript accessibility in different formats

( Pdf, E-pub, Full Text, Audio)

- Unceasing customer service

Track the below URL for one-step submission https://juniperpublishers.com/online-submission.php 